Check for updates

Cite this: RSC Adv., 2017, 7, 53064

Received 10th August 2017

Accepted 10th November 2017

DOI: $10.1039 / c 7 r a 08859 k$

rsc.li/rsc-advances

\section{Synthesis and characterization of two-component acidic ion intercalated layered double hydroxide and its use as a nanoflame-retardant in ethylene vinyl acetate copolymer (EVA)}

\begin{abstract}
Xiuhua Zhou, ab Hong Chen, (DD *a Qinghua Chen ${ }^{\text {a }}$ and Qidan Ling*a
A series of two-component acidic ion intercalated layered double hydroxides ( $\mathrm{MgAlZn}-\mathrm{X}_{1} / \mathrm{X}_{2}-\mathrm{LDHs}$ ) were synthesized by coprecipitation under microwave crystallization, and were further used as novel nanoflame-retardants for ethylene vinyl acetate (EVA). Various measurement methods have been employed to characterize the structure, morphology, thermal stability and combustible properties of the MgAlZn- $X_{1} / X_{2}$-LDHs and MgAlZn- $X_{1} / X_{2}$-LDHs/EVA nanocomposites. The results revealed that MgAIZn-LDHs were intercalated by different two-component acidic ions successfully, and nano-sized particles of MgAlZn- $X_{1} / X_{2}$-LDHs were achieved. The incorporation of $M g A l Z n-X_{1} / X_{2}-L D H s$ into EVA not only can significantly improve the thermal stability of EVA but also improve the thermal oxidative resistance. Compared with pure EVA (LOI = 19, no char yield), the limit oxygen index (LOI) values and char yield of $\mathrm{MgAlZn}-\mathrm{SnO}_{3}{ }^{2-} / \mathrm{CO}_{3}{ }^{2-}-\mathrm{LDHs} / \mathrm{EVA}$ (40/60) nanocomposite increased, reaching $29 \%$ and $28.40 \%$, respectively. Meanwhile, the max smoke density (MSD) values and underwriters laboratories test (UL-94) of $\mathrm{MgAlZn}-\mathrm{SnO}_{3}{ }^{2-} / \mathrm{CO}_{3}{ }^{2-}-\mathrm{LDHs} / \mathrm{EVA}$ nanocomposite decreased by 2.98 and reached a UL-94 V-0 rating, respectively. The improvement of flame retardancy and smoke suppression of $\mathrm{MgAlZn}-\mathrm{SnO}_{3}{ }^{2-} / \mathrm{CO}_{3}{ }^{2-}-\mathrm{LDHs} / \mathrm{EVA}$ nanocomposite can be attributed to the intercalation of flame retardant elements into the $\mathrm{LDH}$ interlayer and laminate, and the synergistic flame retardant effects between two-component acidic ions, evidenced by the dramatically reduced peak heat release $(68.5 \%$ reduction), total heat release values $(22.2 \%$ reduction) and peak smoke production rate $(71.2 \%$ reduction) obtained from cone calorimeter tests, as compared with that of pure EVA. As such, $\mathrm{MgAlZn}-\mathrm{SnO}_{3}{ }^{2-} / \mathrm{CO}_{3}{ }^{2-}$ - $\mathrm{LDH}$ could be applied as a promising high-efficiency flame retardant with the function of smoke suppression.
\end{abstract}

\section{Introduction}

Fire hazards and flame retardant problems have drawn more and more research attention over the world. ${ }^{1-4}$ Currently, halogen flame retardants (FRs) are widely used, however, the combustion of halogens in FRs can give off a large amount of smoke, and toxic and corrosive gases, which can lead to subsequent disaster during burning., ${ }^{5,6}$ To overcome these issues, both academic and industrial communities have been devoted to developing halogen-free flame retardants. ${ }^{7,8}$ Most of the polymer products are potentially a fire hazard for their inherent flammability (LOI $=17-20$ ), such as ethylene vinyl acetate (EVA) copolymer. EVA is an important thermoplastic elastomer used in many fields, including the wire and cable

${ }^{a}$ Fujian Key Laboratory of Polymer Materials, College of Chemistry and Materials Science, Fujian Normal University, Fuzhou, 350007, China. E-mail: lingqd@fjnu. edu.cn; chengh5678@126.com

${ }^{b}$ Fujian Inspection and Research Institute for Product Quality, Fuzhou, 350002, China industries, ${ }^{9}$ encapsulation, adhesives and the drug industry, ${ }^{10}$ etc. Therefore, reducing the fire hazards of EVA is critical, especially in some fields where high fire resistance is required. The high loading of inorganic fillers $(60-65 \%)$ is usually required to obtain a satisfactory flame retardancy of EVA composites, especially aluminum hydroxide (ALH) ${ }^{9,11}$ and magnesium hydroxide (MH). ${ }^{12,13}$ Nevertheless, such high amounts have negatively impact on processing characteristics and mechanical properties. ${ }^{14}$ Therefore, it is significant to search for some other effective flame retardants to replace $\mathrm{MH}$ and ALH.

Layered double hydroxides (LDHs) have received particular attention due to their unique properties, which make it promising for applications such as catalysis, ${ }^{15,16}$ medicine, ${ }^{17,18}$ sorbents, ${ }^{19,20}$ photoelectricity, ${ }^{21,22}$ and flame retardants ${ }^{23-25}$ and so on. Its formulation is usually described as $\left[\mathrm{M}_{1-x}{ }^{2+} \mathrm{M}_{x}{ }^{3+}\right.$ $\left.(\mathrm{OH})_{2}\right]^{x+}\left(\mathrm{A}^{n-}\right)_{x / n} \cdot m \mathrm{H}_{2} \mathrm{O}$, where $\mathrm{M}^{2+}, \mathrm{M}^{3+}$ represented divalent $\left(\mathrm{Mg}^{2+}, \mathrm{Zn}^{2+}, \mathrm{Ni}^{2+}, \mathrm{Cu}^{2+}\right.$, etc. $)$ and trivalent cations $\left(\mathrm{Al}^{3+}, \mathrm{Fe}^{3+}\right.$, $\mathrm{Co}^{3+}, \mathrm{Cr}^{3+}$, etc. $)$ respectively. $\mathrm{X}$ is the $\mathrm{M}^{3+} /\left(\mathrm{M}^{2+}+\mathrm{M}^{3+}\right)$ molar ratio 
which may be varied over a wide range, giving rise to a large class of isostructural materials. ${ }^{26} \mathrm{~A}^{n-}$ is an anion inorganic and organic anions charged such as $\mathrm{NO}_{3}{ }^{-}, \mathrm{CO}_{3}{ }^{2-}, \mathrm{BO}_{2}{ }^{-}, \mathrm{PO}_{4}{ }^{3-}$, $\mathrm{SnO}_{3}{ }^{2-}, \mathrm{SiO}_{3}{ }^{2-}, \mathrm{Cl}^{-}$, etc. The structure of LDHs is similar to the layered magnesium hydroxide in the brucite mineral, whereas the substitution of divalent cations by trivalent cations in the LDHs layers creates a positive charge on the surface, which is balanced by the interlayer anions. ${ }^{1}$

Benefiting from the layered crystalline geometry, ${ }^{27}$ tunable properties, ${ }^{28}$ ability to intercalate various interlayer anions, ${ }^{29}$ and halogen-free, fire-retarding smoke-suppressing, LDHs display great potential as flame retardants., ${ }^{7,27,30,31}$ Industrial production and application of MgAl-LDHs flame retardant have received extensive attention in recent. ${ }^{32-34}$ To further improve the flame retardancy, and to make LDHs more compatible with polymers, the most effectively modified method is intercalating flame retardant elements into the LDHs interlayer and laminate. ${ }^{35}$ Researches show that the anions exist in the space of the LDHs interlayers replaced by anions, which possess flame retardancy and smoke suppression properties ${ }^{36}$ (borate anions, ${ }^{37}$ phosphate anions, ${ }^{38,39}$ silicate anions ${ }^{9,35}$ and stannate anions, ${ }^{\mathbf{1}}$ etc.) can improve the flame retardancy and smoke suppression of composites. Nevertheless, so far reports only focus on single-component acidic ion as intercalated anion. ${ }^{39,40}$ When they applied alone as FRs additives, these intercalated LDHs must be together with other synergistic FRs additives to improve flame retardancy and reduce FRs loading level.

A hybrid from two components usually exhibits good synergistic effect with flame retardant and smoke suppression. ${ }^{36,41}$ In this work, a series of two-component acidic ions $\left(\mathrm{BO}_{2}{ }^{-} / \mathrm{CO}_{3}{ }^{2-}\right.$ (1:1), $\mathrm{PO}_{4}{ }^{3-} / \mathrm{CO}_{3}{ }^{2-}(1: 1), \mathrm{SiO}_{3}{ }^{2-} / \mathrm{CO}_{3}{ }^{2-}(1: 1)$, and $\mathrm{SnO}_{3}{ }^{2-}$ / $\left.\mathrm{CO}_{3}{ }^{2-}(1: 1)\right)$ intercalated layered double hydroxide (MgAlZn-X $/$ $\mathrm{X}_{2}$-LDHs) were synthesized by coprecipitation under microwave crystallization. To the best of our knowledge, this is the first instance that two-component acidic ions were intercalated into layered double hydroxide and were further applied as a nanoflame-retardant in EVA (MgAlZn-X $\mathrm{X}_{1} / \mathrm{X}_{2}$-LDHs/EVA nanocomposites). MgAlZn-LDHs intercalated with various acidic radical may combine the advantages of $\mathrm{Mg}(\mathrm{OH})_{2}, \mathrm{Al}(\mathrm{OH})_{3}$ and metallic compounds (zinc borate, zinc phosphate, zinc silicate, zinc stannate). During combustion, MgAlZn- $\mathrm{X}_{1} / \mathrm{X}_{2}$-LDHs lose interlayer water, producing water vapor and reducing the temperature. Different intercalated anions decompose into their corresponding compounds, carbonate ions decomposes into carbon dioxide dilute the concentration of $\mathrm{O}_{2}$ in the gas phase, other intercalated anions were hydroxylated into mixed metal oxide act as "char reinforcers" or "char expanders" in the condensed phase. ${ }^{42}$ The char residue (metal oxide) formed during combustion that inhibits volatilization of flammable gas during the decomposition process of MgAlZn-LDHs/EVA nanocomposites which isolates oxygen and reduces heat transmission.

\section{Experimental}

\section{Materials}

All chemicals used in the preparation were analytical grade without further purification. $\mathrm{Mg}\left(\mathrm{NO}_{3}\right)_{2} \cdot 6 \mathrm{H}_{2} \mathrm{O}, \mathrm{Al}\left(\mathrm{NO}_{3}\right)_{3} \cdot 9 \mathrm{H}_{2} \mathrm{O}$,
$\mathrm{Zn}\left(\mathrm{NO}_{3}\right)_{2} \cdot 6 \mathrm{H}_{2} \mathrm{O}, \mathrm{NaBO}_{2} \cdot 4 \mathrm{H}_{2} \mathrm{O}, \mathrm{Na}_{3} \mathrm{PO}_{4} \cdot 12 \mathrm{H}_{2} \mathrm{O}, \mathrm{Na}_{2} \mathrm{SiO}_{3} \cdot 9 \mathrm{H}_{2} \mathrm{O}$, $\mathrm{Na}_{2} \mathrm{SnO}_{3} \cdot 4 \mathrm{H}_{2} \mathrm{O}, \mathrm{Na}_{2} \mathrm{CO}_{3}$ and $\mathrm{NaOH}$ were obtained from Sinopharm Chemical Reagent Co. Ltd. Ethylene-vinyl acetate copolymer (EVA28 contains 28 wt\% of vinyl acetate) was purchased from DuPont Company. Deionized water was used for all experiments unless otherwise stated.

\section{Preparation of flame retardant LDHS (MgAlZn- $\mathbf{X}_{1} / \mathrm{X}_{2}$-LDHs)}

$\mathrm{Mg}_{4} \mathrm{Al}_{2} \mathrm{Zn}_{2}-\mathrm{X}_{1} / \mathrm{X}_{2}$-LDHs were prepared via a coprecipitation process. Added $46.89 \mathrm{~g} \mathrm{Al}\left(\mathrm{NO}_{3}\right)_{3} \cdot 9 \mathrm{H}_{2} \mathrm{O}$ into $500 \mathrm{~mL}$ DI water with stirring, this was considered as solution A. Added $37.19 \mathrm{~g}$ $\mathrm{Zn}\left(\mathrm{NO}_{3}\right)_{2} \cdot 6 \mathrm{H}_{2} \mathrm{O}$ and $64.10 \mathrm{~g} \mathrm{Mg}\left(\mathrm{NO}_{3}\right)_{2} \cdot 6 \mathrm{H}_{2} \mathrm{O}$ into $500 \mathrm{~mL}$ DI water with stirring, it was solution $\mathrm{B}$. Solution $\mathrm{C}$ was prepared by added $3.31 \mathrm{~g}$ sodium salt $\left(\mathrm{NaX}_{1}\right)$ and $8.62 \mathrm{~g}$ sodium salt $\left(\mathrm{NaX}_{2}\right)$ into $500 \mathrm{~mL}$ DI water with stirring, in which the molar ratio was varied according to Table 1 . Solution A and solution $\mathrm{B}$ were slowly drop-wise simultaneously into solution C. The $\mathrm{pH}$ adjusted to the range of 11.0-14.0 with $\mathrm{NaOH}$ solution. The slurries were subsequently treated under microwave for 15 minutes. The resulting slurries were kept at $80{ }^{\circ} \mathrm{C}$ for $6 \mathrm{~h}$. The precipitates were washed with DI water and adjusted the $\mathrm{pH}$ to 7.0-8.0, and then dried in an oven at $80^{\circ} \mathrm{C}$. The resulting LDHs were acidic ions $\left(\mathrm{CO}_{3}{ }^{2-}, \mathrm{BO}_{2}{ }^{-}, \mathrm{PO}_{4}{ }^{3-}, \mathrm{SnO}_{3}{ }^{2-}, \mathrm{SiO}_{3}{ }^{2-}\right)$ hybrid intercalated $\mathrm{LDHs}$ labeled as $\mathrm{MgAlZn}-\mathrm{BO}_{2}{ }^{-} / \mathrm{CO}_{3}{ }^{2-}$-LDHs, MgAlZn- $\mathrm{PO}_{4}{ }^{3-} / \mathrm{CO}_{3}{ }^{2-}$-LDHs, MgAlZn-SiO${ }_{3}{ }^{2-} / \mathrm{CO}_{3}{ }^{2-}$-LDHs, and MgAlZn-SnO ${ }_{3}{ }^{2-} / \mathrm{CO}_{3}{ }^{2-}$-LDHs (short for FR-1, FR-2, FR-3, FR-4, respectively).

\section{Preparation of FR/EVA nanocomposites}

The required amounts of EVA resin and various FRs (40\% in nanocomposites) were melted and blended in a HAAKE torque rheometer for $10 \mathrm{~min}$ with a rotor speed of $60 \mathrm{rpm}$ to make the FRs dispersed evenly in the resin. After that, the mixture was hot pressed at $143{ }^{\circ} \mathrm{C}$ under $10 \mathrm{MPa}$ using a plate vulcanizer. The resulting FRs/EVA nanocomposites samples were named as FR1/EVA, FR-2/EVA, FR-3/EVA and FR-4/EVA, respectively. Pure EVA sample was also prepared using the same method for comparison.

\section{Characterization}

The X-ray diffraction (XRD) patterns were recorded on an X'Pert Pro MPD type powder X-ray diffractometer (Holland Panalytical company) with $\lambda=1.54184 \AA$. The data were collected with $\mathrm{Cu}$ $\mathrm{K} \alpha$ tube irradiation operated at $40 \mathrm{kV}$ and $40 \mathrm{~mA}$. The scanning rate was $5^{\circ} \min ^{-1}$ in the range of $5-80^{\circ}$. According to X-ray diffraction results, crystallite size and basal spacing were

Table 1 The molar ratio of sodium salt $\left(\mathrm{NaX}_{1}\right)$ and sodium salt $\left(\mathrm{NaX}_{2}\right)$

\begin{tabular}{llll}
\hline Samples & Sodium salt $\left(\mathrm{NaX}_{1}\right)$ & $\begin{array}{l}\text { Sodium salt } \\
\left(\mathrm{NaX}_{2}\right)\end{array}$ & $\begin{array}{l}\text { Mole ratio of } \\
\text { intercalated anions }\end{array}$ \\
\hline FR-1 & $\mathrm{NaBO}_{2} \cdot 4 \mathrm{H}_{2} \mathrm{O}$ & $\mathrm{Na}_{2} \mathrm{CO}_{3}$ & $2: 1$ \\
FR-2 & $\mathrm{Na}_{3} \mathrm{PO}_{4} \cdot 12 \mathrm{H}_{2} \mathrm{O}$ & $\mathrm{Na}_{2} \mathrm{CO}_{3}$ & $2 / 3: 1$ \\
FR-3 & $\mathrm{Na}_{2} \mathrm{SiO}_{3} \cdot 9 \mathrm{H}_{2} \mathrm{O}$ & $\mathrm{Na}_{2} \mathrm{CO}_{3}$ & $1: 1$ \\
FR-4 & $\mathrm{Na}_{2} \mathrm{SnO}_{3} \cdot 4 \mathrm{H}_{2} \mathrm{O}$ & $\mathrm{Na}_{2} \mathrm{CO}_{3}$ & $1: 1$
\end{tabular}


calculated by Debye-Scherrer equation formula (1) and Bragg equation formula (2), respectively: (1) $L=\lambda / B_{2} \cos \theta$; (2) $d=\lambda /$ $2 \sin \theta$. Where $L$ is the crystallite size of the LDHs (nm), $\lambda$ is the expression of the wavelength of the incident ray with a value of $1.54184 \AA$, $\theta$ is the Bragg diffraction angle $(\theta)$. B is the full width at half maximum (rad.). Fourier transform infrared (FTIR) spectroscopy measurements were performed using an AVATAR 360 type Fourier Transform Infrared Spectrometer (America Thermo Nicolet Company) with a resolution of $4 \mathrm{~cm}^{-1}, 64$ scanning numbers, with a $\mathrm{KBr} / \mathrm{sample}$ mass ratio of $100: 1$. Thermogravimetric analyses (TGA) were performed on STA 449C thermal analyzer (Germany NETZSCH Company) at a scan rate of $10{ }^{\circ} \mathrm{C} \mathrm{min}{ }^{-1}$ under air flow. Limiting oxygen index (LOI) was measured using an HC-2 type oxygen index instrument on testing of bars of size $100 \times 6.5 \times 3 \mathrm{~mm}^{3}$, according to the standard oxygen index test ASTM D2863. Vertical burning test was conducted according to UL-94. The dimensions of samples for UL-94 tests were $127 \times 13 \times 13 \mathrm{~mm}^{3}$. Smoke density test was measured using JCY-2 type smoke density test machine on the test of size $25.0 \times 25.0 \times 3.0 \mathrm{~mm}^{3}$ in accordance to ASTM D2843. The flammability of the samples was also characterized by cone calorimeter (JCZ-2, Jiangning Analytic Instrument company, China), following the procedures in ISO5660. The samples with the dimension of $100 \times 100 \times 4 \mathrm{~mm}^{3}$ were irradiated horizontally at a heat flux of $35 \mathrm{~kW} \mathrm{~m}^{-2}$. The surface morphologies of synthesized FRs, combustion-fractured cross sections and freeze-fractured cross sections of the FRs/EVA sample bars were observed using scanning electron microscope (SEM) (JSM-7500F, JEOL, Japan). Elongation at break and tensile strength were conducted at room temperature with an electronic universal testing instrument (ETM104C, Shenzhen Wan Ce Testing Equipment Co., Ltd., Shenzhen, China) according to ISO 527. All of the material types were evaluated five times to reduce the experimental error.

\section{Results and discussion}

\section{Characterization of MgAlZn- $\mathrm{X}_{1} / \mathrm{X}_{2}$-LDHs}

The XRD patterns of $\mathrm{Mg}_{4} \mathrm{Al}_{2} \mathrm{Zn}_{2}-\mathrm{CO}_{3}{ }^{2-}$-LDHs and $\mathrm{MgAlZn}-\mathrm{X}_{1} /$ $\mathrm{X}_{2}$-LDHs are shown in Fig. 1 . It is noted that all XRD patterns exhibit the typical peaks of LDHs. The peaks of these patterns were ascribed to the characteristic diffraction planes (003), (006) and (009) that reflected the lamellar structures of the LDHs, and the characteristic plane (110) which reflected layer structure of the LDHs, corresponding to hydrotalcite-like materials which also establish the purity of the LDHs obtained from the coprecipitation method. The diffraction peaks are narrow and sharp without other impurity peaks, indicating that these MgAlZn- $\mathrm{X}_{1} / \mathrm{X}_{2}$-LDHs have good crystallinity and single crystalline phase. Thus, the two-component acidic ions intercalated LDHs samples still maintain the lamellar structure of typical LDHs.

Average crystallite sizes of MgAlZn- $\mathrm{X}_{1} / \mathrm{X}_{2}$-LDHs samples were calculated according to the formula (1). The results are listed in Table 2. It can be seen that the average crystallite sizes of the samples under microwave crystallization are in the range of 13.93-25.88 nm. The inter layer distance with respect to the first

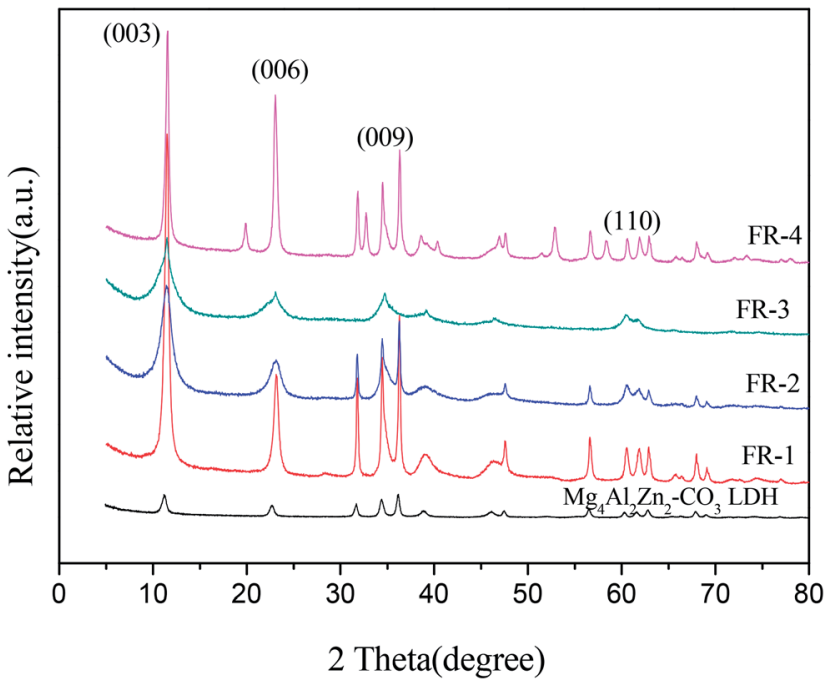

Fig. 1 XRD patterns of FRs and $\mathrm{Mg}_{4} \mathrm{Al}_{2} \mathrm{Zn}_{2}-\mathrm{CO}_{3}{ }^{2-}-\mathrm{LDHs}$.

basal reflection (003) can be calculated by using the formula (2). The results are also listed in Table 2 . It is found that the values of the layer spacing $\left(d_{003}\right)$ are similar. However, the diffraction peaks position near $2 \theta=60.6^{\circ}$ (110) of the samples haven't been changed. The result of XRD analysis suggests that the intercalation of two-component acidic ions doesn't change the lamellar structure of the MgAlZn- $\mathrm{X}_{1} / \mathrm{X}_{2}$-LDHs.

The LDHs nanoparticles prepared by direct precipitation method tend to agglomerating during preparation, and thus have larger particle size which can lead to poor dispersibility in EVA matrix. In order to overcome this problem, microwave crystallization was employed to prepare $\mathrm{MgAlZn}-\mathrm{X}_{1} / \mathrm{X}_{2}-\mathrm{LDHs}$ instead. The obtained LDHs nanoparticles have relatively higher crystallinity and smaller average crystallite sizes distribution. It is suggested that the Lorentz force of microwave field can act on the ions (such as $\mathrm{Mg}^{2+}, \mathrm{Al}^{3+}, \mathrm{Zn}^{2+}, \mathrm{OH}^{-}, \mathrm{CO}_{3}{ }^{2-}$, etc.) and polar molecules (such as $\mathrm{H}_{2} \mathrm{O}$ etc.), and prevent agglomerating of the LDHs nanoparticles during preparation.

FTIR spectra of FR-1, FR-2, FR-3, FR-4 are shown in Fig. 2. It can be seen that the absorption bands appear in the range of $3450-3550 \mathrm{~cm}^{-1}$ and around $1577 \mathrm{~cm}^{-1}$ were attributed to $\nu_{\mathrm{OH}}$ symmetric stretching vibration due to the presence of hydroxyl group of hydroxides, physically adsorbed water molecule and $\nu_{\mathrm{H}-\mathrm{O}-\mathrm{H}}$ bending vibrations, respectively. ${ }^{43}$ It is coincident with the fact that considerable amounts of $\mathrm{H}_{2} \mathrm{O}$ molecules were absorbed on the surface of the samples or have been

Table 2 The crystallite size and basal spacing of FRs and $\mathrm{Mg}_{4} \mathrm{Al}_{2} \mathrm{Zn}_{2^{-}}$ $\mathrm{CO}_{3}^{2-}-\mathrm{LDH}$

\begin{tabular}{lll}
\hline Samples & $\begin{array}{l}\text { Crystallite } \\
\text { size }(L) / \mathrm{nm}\end{array}$ & $\begin{array}{l}\text { Layer spacing } \\
\left(d_{003}\right) / \mathrm{nm}\end{array}$ \\
\hline $\mathrm{Mg}_{4} \mathrm{Al}_{2} \mathrm{Zn}_{2}-\mathrm{CO}_{3}{ }^{2-}$-LDH & 47.80 & 0.778 \\
$\mathrm{FR}-1$ & 20.08 & 0.771 \\
$\mathrm{FR}-2$ & 14.60 & 0.774 \\
$\mathrm{FR}-3$ & 13.93 & 0.771 \\
FR-4 & 25.88 & 0.770
\end{tabular}




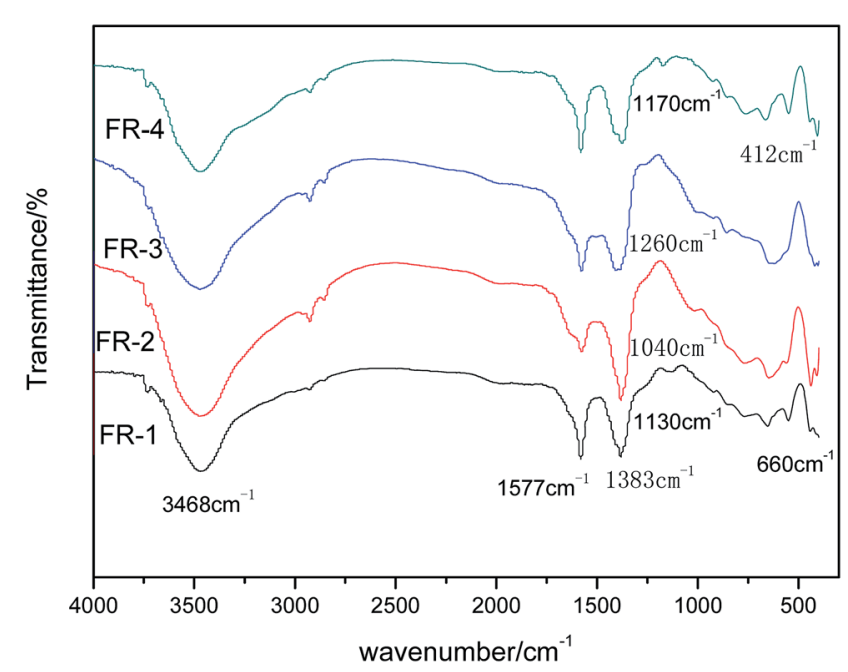

Fig. 2 FTIR spectra of FRs under microwave crystallization.

intercalated space lattice interlamination, the lower values of $\nu_{\mathrm{OH}}$ symmetric stretching vibration in these compounds compared to that of free $\mathrm{OH}$ group $\left(3468 \mathrm{~cm}^{-1}\right)$ indicates that all the $\mathrm{OH}$ groups are involved in hydrogen bonding with layer and interlayer. The absorption band at around the range of 412$660 \mathrm{~cm}^{-1}$ was attributed to laminate surface O-M-O (M was $\mathrm{Zn}$, $\mathrm{Mg}$, Al) group; ${ }^{44}$ the band at $1383 \mathrm{~cm}^{-1}$ was due to $\mathrm{CO}_{3}{ }^{2-}$ characteristics stretching vibration in the $\mathrm{FRs}^{45}$ The FTIR spectrum of the FR-1 shows that the band at $1130 \mathrm{~cm}^{-1}$ can be attributed to $\mathrm{BO}_{2}{ }^{-}$characteristics stretching vibration. ${ }^{40}$ In the FR-2, the band at $1040 \mathrm{~cm}^{-1}$ can be attributed to $\mathrm{PO}_{4}{ }^{3-}$ characteristics stretching vibration, ${ }^{39,46}$ while the band at $1260 \mathrm{~cm}^{-1}$ can be attributed to $\mathrm{SiO}_{3}{ }^{2-}$ characteristics stretching vibration in the FR-3; the band at $1170 \mathrm{~cm}^{-1}$ is the specific characteristics stretching vibration of $\mathrm{SnO}_{3}{ }^{2-}$ as presented in $\mathrm{FR}-4^{1}$. The results of FTIR analysis indicate that two-component acidic ions $\left(\mathrm{BO}_{2}{ }^{-} / \mathrm{CO}_{3}{ }^{2-}, \mathrm{PO}_{4}{ }^{3-} / \mathrm{CO}_{3}{ }^{2-}, \mathrm{SiO}_{3}{ }^{2-} / \mathrm{CO}_{3}{ }^{2-}, \mathrm{SnO}_{3}{ }^{2-} / \mathrm{CO}_{3}{ }^{2-}\right)$ have been intercalated into the LDHs interlayer, respectively.

The morphology and structure of synthesized LDHs are further investigated by SEM. Fig. 3 shows all synthesized LDHs exhibit the crystallites with relatively uniform and thin lamellar particle that looked like rounded hexagonal shapes, which is typical of hydrotalcite-like materials..$^{4,48}$ As commonly observed for the typical inorganic anionic intercalated MgAlZn-LDH compounds and consistent with the results of the XRD analysis. ${ }^{35,49}$ The lateral size ranges of the platelets are similar for FR1, FR-2, FR-3 and FR-4, nearly $100 \mathrm{~nm}$.

\section{Thermal degradation: mass loss}

TG/DTG curves for pure EVA and FRs/EVA nanocomposites are shown in Fig. 4. The data are listed in Table 3. As can be observed, the pure EVA undergoes one-stage degradation at higher temperature with the final residue at $800{ }^{\circ} \mathrm{C}$ near to zero. The FRs/EVA show three-stage thermal degradation processes in the temperature range of $50-800{ }^{\circ} \mathrm{C}$. The first thermal degradation stage occurs due to the removal of interlayer water in the LDHs, as showed in eqn (1); the second thermal degradation stage occurs due to the elimination of the hydroxyl groups in the layers and interlayer carbonate ions decomposes into carbon dioxide, other different inorganic acids decompose into their corresponding compounds, as showed in eqn (2), which leads to breaking of the layered structures; ${ }^{50}$ the third thermal degradation stage occurs due to the conversion of the

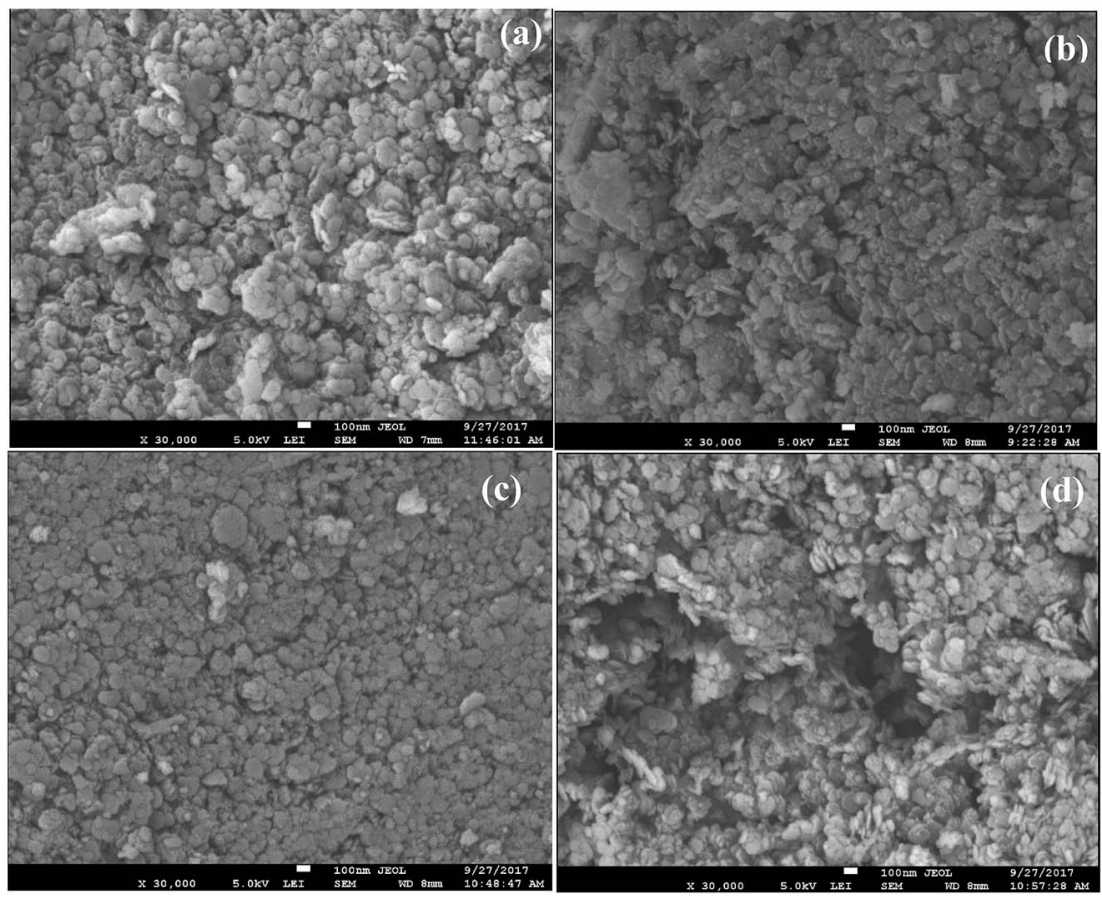

Fig. 3 SEM images of (a) FR-1, (b) FR-2, (c) FR-3 and (d) FR-4. 

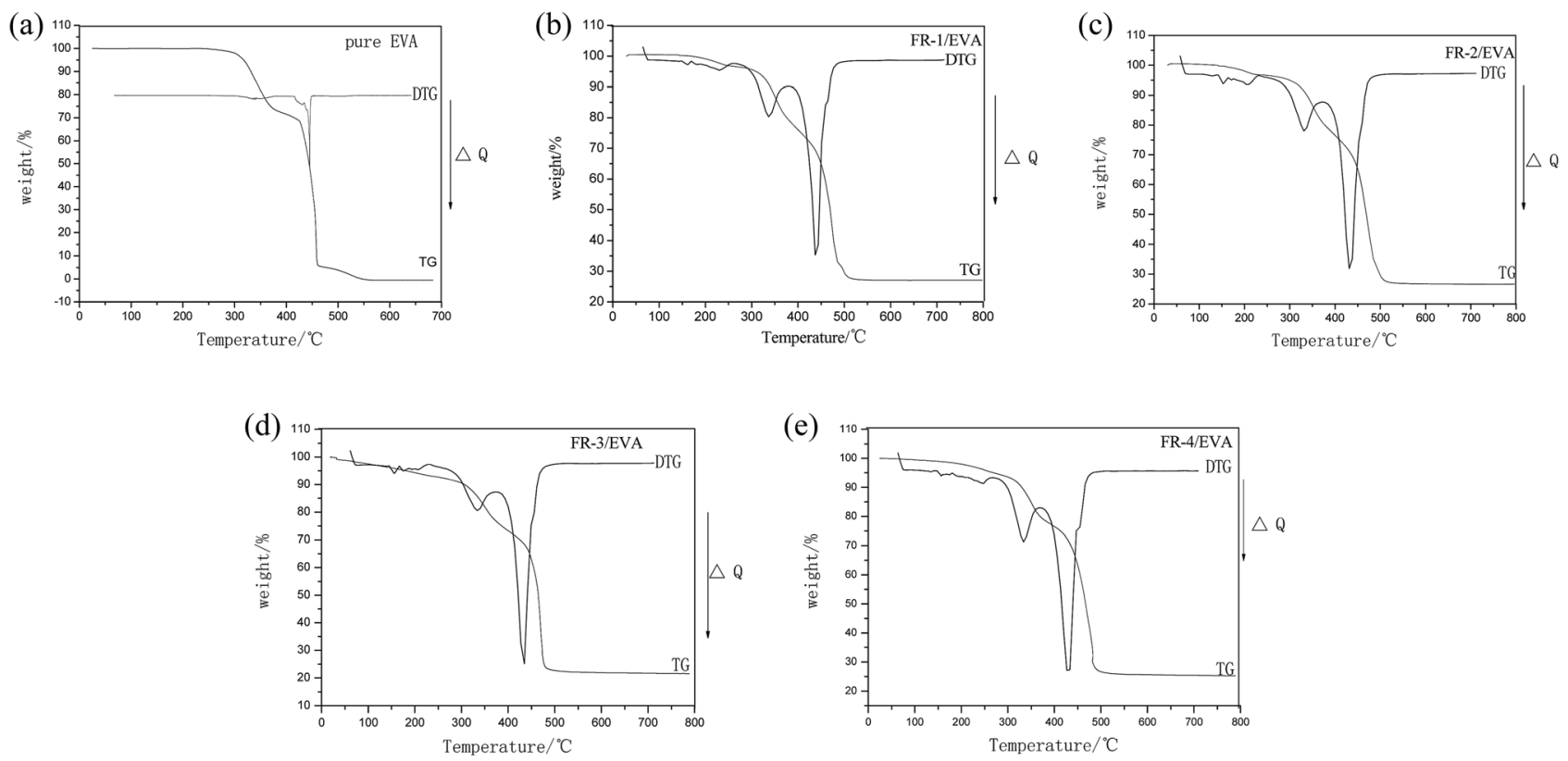

Fig. 4 TG-DTG curves of (a) pure EVA, (b) FR-1/EVA, (c) FR-2/EVA, (d) FR-3/EVA, (e) FR-4/EVA.

Table 3 Data for TG and DTG of pure EVA and FRs/EVA nanocomposites

\begin{tabular}{llllll}
\hline & & \multicolumn{2}{l}{} & \\
\cline { 3 - 4 } & $\begin{array}{l}T_{\text {max }}{ }^{b}\left({ }^{\circ} \mathrm{C}\right) \\
\left({ }^{\circ} \mathrm{C}\right)\end{array}$ & $\begin{array}{l}\text { First } \\
\text { Stage }\end{array}$ & $\begin{array}{l}\text { Second } \\
\text { stage }\end{array}$ & $\begin{array}{l}\text { Three } \\
\text { stage }\end{array}$ & $\begin{array}{l}\text { Char } \\
\text { residues }\end{array}$ \\
\hline Pure EVA & 420 & 442 & - & - & 0 \\
FR-1/EVA & 178 & 224 & 350 & 436 & 27.15 \\
FR-2/EVA & 188 & 206 & 348 & 436 & 26.65 \\
FR-3/EVA & 202 & 209 & 338 & 436 & 26.13 \\
FR-4/EVA & 214 & 246 & 350 & 437 & 28.40
\end{tabular}

${ }^{a} T_{\text {onset: }}$ the onset degradation temperature. ${ }^{b} T_{\text {max }}$ : maximum weight loss temperature.

LDHs into a mixed metal oxide, including magnesium oxide, aluminum oxide, zinc oxide, as showed in eqn (3), which can promote the formation of a thermal charring at the surface of the composites.

The first thermal degradation stage:

$$
\begin{aligned}
{\left[\mathrm{Mg}_{4} \mathrm{Al}_{2} \mathrm{Zn}_{2}(\mathrm{OH})_{16} \mathrm{X}_{1} \mathrm{X}_{2}\right] \cdot 4 \mathrm{H}_{2} \mathrm{O} \rightarrow } & \rightarrow\left[\mathrm{Mg}_{4} \mathrm{Al}_{2} \mathrm{Zn}_{2}(\mathrm{OH})_{16} \mathrm{X}_{1} \mathrm{X}_{2}\right]+4 \mathrm{H}_{2} \mathrm{O}
\end{aligned}
$$

(wherein, $\mathrm{X}_{1}$ are $2 \mathrm{BO}_{2}{ }^{-}, 2 / 3 \mathrm{PO}_{4}{ }^{3-}, \mathrm{SiO}_{3}{ }^{2-}, \mathrm{SnO}_{3}{ }^{2-}, \mathrm{X}_{2}$ is $\mathrm{CO}_{3}{ }^{2-}$ ). The second thermal degradation stage:

$$
\mathrm{Mg}_{4} \mathrm{Al}_{2} \mathrm{Zn}_{2}(\mathrm{OH})_{16} \mathrm{X}_{1} \mathrm{X}_{2} \rightarrow \mathrm{Mg}_{4} \mathrm{Al}_{2} \mathrm{Zn}_{2}+8 \mathrm{H}_{2} \mathrm{O}+\mathrm{M}+\mathrm{CO}_{2}
$$

(wherein, $\mathrm{M}$ are the corresponding oxides of $\mathrm{X}_{1}, \mathrm{M}$ are $\mathrm{B}_{2} \mathrm{O}_{3}$, $1 / 3 \mathrm{P}_{2} \mathrm{O}_{5}, \mathrm{SiO}_{2}, \mathrm{SnO}_{2}$ ).

The third thermal degradation stage:

$$
\mathrm{Mg}_{4} \mathrm{Al}_{2} \mathrm{Zn}_{2}+\mathrm{O}_{2} \rightarrow 4 \mathrm{MgO}+\mathrm{Al}_{2} \mathrm{O}_{3}+2 \mathrm{ZnO}
$$

The char residues remaining at $800{ }^{\circ} \mathrm{C}$ were $0 \%, 27.15 \%$, $26.65 \%, 26.13 \%, 28.40 \%$, respectively. The residue percentages of the FRs/EVA were much higher than that of pure EVA, indicating that the incorporation of $\mathrm{MgAlZn}-\mathrm{X}_{1} / \mathrm{X}_{2}$-LDHs significantly improves the thermal oxidative resistance. It is observed that FR-4/EVA leaves the more char residues to promote formation of compact charred layers than that of pure EVA, FR1/EVA, FR-2/EVA and FR-3/EVA. It shows that the synergistic flame retardant effects between two-component acidic ions $\mathrm{SnO}_{3}{ }^{2-}$ and $\mathrm{CO}_{3}{ }^{2-}\left(\mathrm{SnO}_{3}{ }^{2-} / \mathrm{CO}_{3}{ }^{2-}=1: 1\right)$ improves more effectively thermal oxidative resistance than the effects between other two-component acidic ions $\mathrm{BO}_{2}{ }^{-} / \mathrm{CO}_{3}{ }^{2-}, \mathrm{PO}_{4}{ }^{3-} / \mathrm{CO}_{3}{ }^{2-}$, $\mathrm{SiO}_{3}{ }^{2-} / \mathrm{CO}_{3}{ }^{2-}$. These charred layers slow down heat and mass transfer between the gas and condensed phases and prevent the underlying polymeric substrate from further attack by heat flux in a flame.

\section{Flame retardancy}

The flame-retardant behavior of pure EVA and FRs/EVA nanocomposites was characterized by three widely used test methods: limit oxygen index (LOI), vertical burning test (UL-94) and smoke density test. The results are presented in Table 4.

The inflammability of pure EVA and FRs/EVA nanocomposites was measured. As can be seen from Table 4 that the LOI value of pure EVA is only $19 \%$, and with the additive amount of LDHs in EVA up to $40 \mathrm{wt} \%$, the LOI values of FR-1/ EVA, FR-2/EVA, FR-3/EVA and FR-4/EVA are increased to $25 \%$, $25 \%, 24 \%$ and $29 \%$, respectively. It indicates that the additive of FRs can effectively improve the flame retardant properties of EVA. It was noted that FR-4/EVA (40/60) expressed higher LOI value and lower max smoke density (MSD) value than that of FR1/EVA, FR-2/EVA and FR-3/EVA. This result confirms the synergistic flame retardant effects between two-component 
Table 4 Flame retardant properties of pure EVA and FRs/EVA nanocomposites

\begin{tabular}{llllr}
\hline Samples & Additive amount (\%) & LOI (\%) & UL-94 & MSD \\
\hline Pure EVA & 0 & 19 & Dripping & 26.94 \\
FR-1/EVA & 40 & 25 & V-0 & 3.05 \\
FR-2/EVA & 40 & 25 & V-0 & 10.81 \\
FR-3/EVA & 40 & 24 & V-0 & 3.12 \\
FR-4/EVA & 40 & 29 & V-0 & 2.98
\end{tabular}

acidic ions $\mathrm{SnO}_{3}{ }^{2-}$ and $\mathrm{CO}_{3}{ }^{2-}\left(\mathrm{SnO}_{3}{ }^{2-} / \mathrm{CO}_{3}{ }^{2-}=1: 1\right)$. Moreover, the UL-94 vertical burning test of FR-1/EVA, FR-2/EVA, FR3/EVA and FR-4/EVA passed UL-94 V-0 rating, however, pure EVA was completely degraded with gradual dripping.

\section{Cone calorimeter test (CCT)}

The cone calorimeter test is used to simulates the burning behavior of materials in real-world fire scenarios, it showing prime significance in the research and development of new flame-retardant materials. ${ }^{\mathbf{5 1}}$ The parameters typically available from the cone calorimeter test include the heat release rate (HRR) and its peak values (pk-HRR), the total heat release (THR), the smoke production rate (SPR) and its peak value (pkSPR), time-to-ignition (TTI), fire growth rate index (FIGRA). The fire and smoke properties of pure EVA and FRs/EVA (40/60) nanocomposites were shown in Fig. 5-7 and Table 5.

\section{Heat release rate (HRR)}

The heat release rate (HRR) is a key value due to it expresses the intensity of a fire. ${ }^{52}$ The HRR curves of pure EVA and FRs/EVA nanocomposites are shown in Fig. 5 and the corresponding data are listed in Table 5. There is one peak in the HRR curve of pure EVA while there are three peaks in the curves of FRs/EVA, which were attributed to the decomposition of LDHs, consistent with thermal degradation stage in eqn (1)-(3) and Fig. 4. With

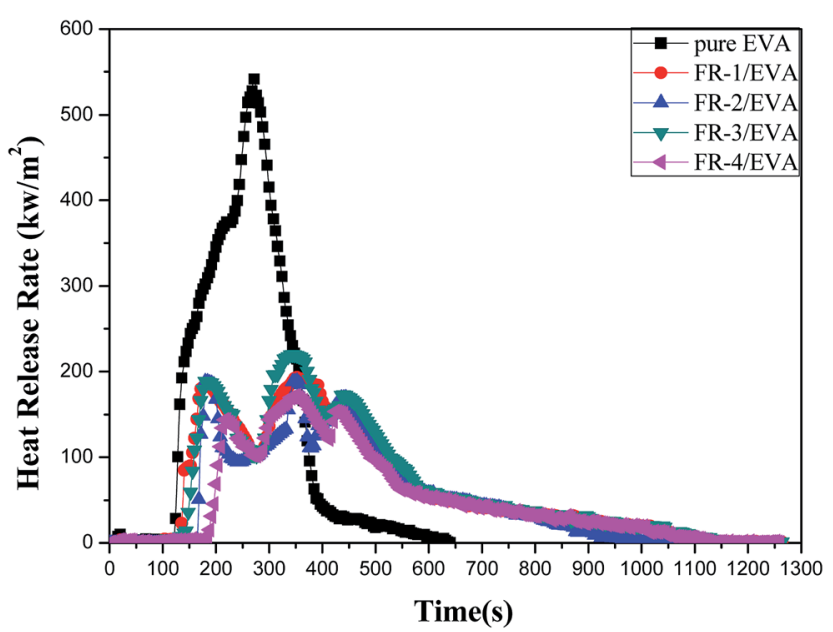

Fig. 5 Heat release rate (HRR) of pure EVA and FRs/EVA nanocomposites at a flux of $35 \mathrm{~kW} \mathrm{~m}^{-2}$.
Table 5 Cone calorimetric results for pure EVA and FRs/EVA nanocomposites (heat flux of $35 \mathrm{~kW} \mathrm{~m}^{-2}$ )

\begin{tabular}{llllll}
\hline Samples & TTI $(\mathrm{s})$ & $\begin{array}{l}\text { pk-HRR } \\
\left.(\mathrm{kW} \mathrm{m})^{-2}\right)\end{array}$ & $\begin{array}{l}\text { THR } \\
\left(\mathrm{MJ} \mathrm{m} \mathrm{m}^{-2}\right)\end{array}$ & $\begin{array}{l}\text { pk-SPR } \\
\left(\mathrm{m}^{2} \mathrm{~s}^{-1}\right)\end{array}$ & $\begin{array}{l}\text { FIGRA } \\
\left(\mathrm{kW} \mathrm{m}^{-2} \mathrm{~s}^{-1}\right)\end{array}$ \\
\hline Pure EVA & 119 & 543 & 171 & 0.111 & 2.011 \\
FR-1/EVA & 135 & 193 & 146 & 0.034 & 0.545 \\
FR-2/EVA & 165 & 189 & 143 & 0.078 & 0.536 \\
FR-3/EVA & 133 & 219 & 154 & 0.037 & 0.633 \\
FR-4/EVA & 190 & 171 & 133 & 0.032 & 0.488
\end{tabular}

the addition of MgAlZn- $\mathrm{X}_{1} / \mathrm{X}_{2}$-LDHs, the peak HRR (pk-HRR) of FR-1/EVA, FR-2/EVA, FR-3/EVA and FR-4/EVA were decreased by $64.5 \%, 65.2 \%, 59.7 \%, 68.5 \%$, respectively, which indicates the good flame retardation of FRs for EVA. That is mainly because of the physical barrier effect of LDH layers and the metal oxide produced during the combustion process, which could isolate oxygen and prevent the volatilization of combustible gas during the decomposition process. It is worthy to note that the pk-HRR value of FR-4/EVA is less than all the others at the same addition (40 wt\%), which is in agreement with its LOI value and UL-94 rating. The result is due to the synergistic effect between twocomponent acidic ions $\mathrm{SnO}_{3}{ }^{2-}$ and $\mathrm{CO}_{3}{ }^{2-}\left(\mathrm{SnO}_{3}{ }^{2-} / \mathrm{CO}_{3}{ }^{2-}=\right.$ $1: 1$ ), and the catalytic charring effect of tin element.

\section{Total heat release (THR)}

The slope of the total heat release (THR) curves can be considered as a representative of the flame spread. ${ }^{53}$ Fig. 6 presents the total heat release rate (THR) curves of pure EVA and FRs/EVA nanocomposites, and the related data are listed in Table 5 . The THR values of all the FRs/EVA nanocomposites were significantly reduced with the addition of $\mathrm{MgAlZn}-\mathrm{X}_{1} / \mathrm{X}_{2}$-LDHs. Compared with pure EVA, the THR values of FR-1/EVA, FR-2/ EVA, FR-3/EVA and FR-4/EVA were decreased by 14.6\%, 16.4\%, 9.9\%, 22.2\%, respectively. Among all samples, FR-4/EVA was decreased most obviously. It is suggested that the synergistic effects between two-component acidic ions $\mathrm{SnO}_{3}{ }^{2-}$ and $\mathrm{CO}_{3}{ }^{2-}$

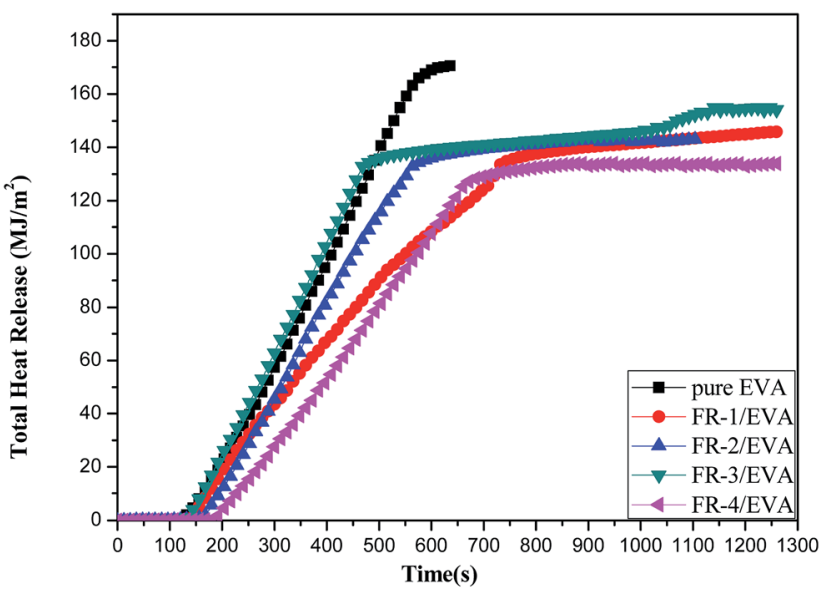

Fig. 6 Total heat release (THR) of pure EVA and FRs/EVA nanocomposites at a flux of $35 \mathrm{~kW} \mathrm{~m}^{-2}$. 
$\left(\mathrm{SnO}_{3}{ }^{2-} / \mathrm{CO}_{3}{ }^{2-}=1: 1\right)$ could promote the formation of a char layer with condensed phase effect, isolating oxygen and preventing the matrix from further combustion.

\section{Smoke production rate (SPR)}

The smoke production rate (SPR) is considered as another important parameter for the flame retarded materials. The SPR curves of pure EVA and FRs/EVA nanocomposites are illustrated in Fig. 7, and the corresponding data are listed in Table 5. It was shown that the SPR values of FRs/EVA were much lower than that of pure EVA. The peak SPR (pk-SPR) value of pure EVA is the highest one $\left(0.111 \mathrm{~m}^{2} \mathrm{~s}^{-1}\right)$ among all samples. After the incorporation MgAlZn- $\mathrm{X}_{1} / \mathrm{X}_{2}$-LDHs, FRs/EVA nanocomposites show the significantly suppress the smoke emission, the pk-SPR values of FRs/EVA are $0.034 \mathrm{~m}^{2} \mathrm{~s}^{-1}, 0.078 \mathrm{~m}^{2} \mathrm{~s}^{-1}, 0.037 \mathrm{~m}^{2} \mathrm{~s}^{-1}$, $0.032 \mathrm{~m}^{2} \mathrm{~s}^{-1}$, respectively. With the same loading (40 wt\%), FR4/EVA performed better than that of other FRs/EVA, which shows lower pk-SPR value, decreased by $71.2 \%$, as compared with pure EVA. Such phenomenon can be described as follows. A larger specific surface area of metal oxide generated from the during combustion process, which can better adsorb smoke, restrain the release of pyrolysis gases and smoke particle efficiently.

In addition, other important parameters obtained from the cone calorimeter test, such as the time-to-ignition (TTI) and fire growth rate index (FIGRA) are summarized in Table 5. The times-to-ignition (TTI) of pure EVA and FRs/EVA nanocomposites are 119 s, 135 s, 165 s, 133 s and 190 s, respectively. The delayed TTI suggests enhanced fire safety. ${ }^{42}$ The increase in the TTI of FRs/EVA was due to the early decomposition of LDH, which absorbs heat and partly decomposes into vapor and $\mathrm{CO}_{2}$.

The fire growth rate index (FIGRA) is parameter calculated from the directly measured data of CCT, ${ }^{54}$ which indicates the burning propensity of a material, has been calculated from the ratio of pk-HRR and time to pk-HRR for all samples. ${ }^{42}$ Compared with the FIGRA value of pure EVA $\left(2.011 \mathrm{~kW} \mathrm{~m}^{-2} \mathrm{~s}^{-1}\right)$, the FIGRA values of FR-1/EVA, FR-2/EVA and FR-3/EVA were

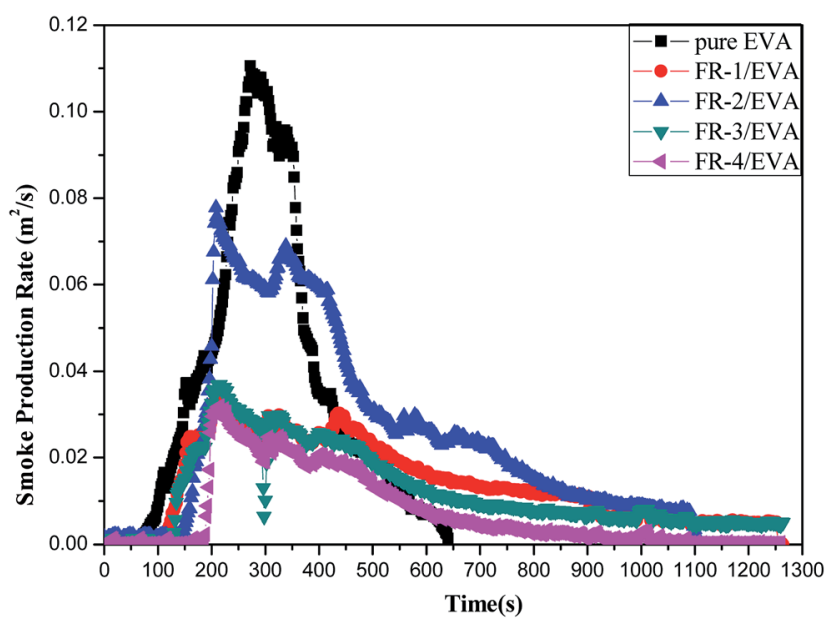

Fig. 7 Smoke production rate (SPR) of pure EVA and FRs/EVA nanocomposites at a flux of $35 \mathrm{~kW} \mathrm{~m}^{-2}$. decreased by $72.9 \%, 73.3 \%$ and $68.5 \%$, respectively. It is worth noting that the FIGRA value of FR-4/EVA is deceased much lower than other FRs/EVA, which reaching 75.7\%. The lowest FIGRA value of FR-4/EVA means the lowest fire hazard of the material.

\section{Digital photographs of carbon residue}

The digital photographs of char residues after CCT for pure EVA and FRs/EVA nanocomposites are shown in Fig. 8. For pure EVA, no charred residues can be observed, it is clear that the charred residues of FR-1/EVA, FR-2/EVA and FR-3/EVA nanocomposites are loose, however, the char residue of the FR-4/EVA nanocomposite is much compact and integrated, and the gray substance is mainly mixed metal oxides $\left(\mathrm{MgO}, \mathrm{Al}_{2} \mathrm{O}_{3}, \mathrm{ZnO}\right.$ and $\mathrm{SnO}_{2}$ ), corresponding to the charred residue in Table 3. The analysis of the charred residues shows that the introduction of LDHs can improve char formation during combustion. Contrast digital photographs of the char residues of the FRs/EVA, it is found that FR-4/EVA has more compact structures than those of other FRs/EVA, which presents the further evidence that synergistic effects between two-component acidic ions $\mathrm{SnO}_{3}{ }^{2-}$ and $\mathrm{CO}_{3}{ }^{2-}\left(\mathrm{SnO}_{3}{ }^{2-} / \mathrm{CO}_{3}{ }^{2-}=1: 1\right)$ significantly could cooperate in obtaining a compact residue. It is well known that the continuous and compact residues layer can prevent the heat and mass transfer between flame zone and burning substrate, and also protect the underlying materials from further burning. ${ }^{51}$

\section{Mechanical properties}

The tensile strength and elongation at break for pure EVA and FRs/EVA nanocomposites with 40 wt $\%$ additive amount of LDHs are shown in the Table 6. The tensile strength values of FR-1/EVA, FR-2/EVA, FR-3/EVA and FR-4/EVA are 12.0 Mpa, 8.06 Mpa, $10.11 \mathrm{Mpa}, 13.38 \mathrm{Mpa}$, respectively. The high additive amount can lead to a rapid decrease in tensile strength compared to that loading with pure EVA, which could be the result of inbomogeneity in the dispersion of the filler, compromising the tensile strength. The filling and suspending of LDHs particles in the polymer matrix have an equivalent effect. When the concentration is high enough, the particles can form agglomerates. The agglomerates can be further closely packed and wrapped in the polymer. When the MgAlZn- $\mathrm{X}_{1} / \mathrm{X}_{2}$ LDHs/EVA nanocomposites were stretched, the existence of agglomerates, which act as the stress concentration point, can lead to poor mechanical properties of the nanocomposites.

Contrast with FRs/EVA in Table 6, it was found that the tensile strength value and elongation at break value of FR-4/EVA decrease slowly than that of FR-1/EVA, FR-2/EVA and FR-3/EVA. This is an indication that the synergistic effects between twocomponent acidic ions $\mathrm{SnO}_{3}{ }^{2-}$ and $\mathrm{CO}_{3}{ }^{2-}\left(\mathrm{SnO}_{3}{ }^{2-} / \mathrm{CO}_{3}{ }^{2-}=\right.$ $1: 1)$ enhance the compatibility LDHs particles with the EVA matrix, acting as reinforcements. When the $\mathrm{MgAlZn}-\mathrm{X}_{1} / \mathrm{X}_{2}$ LDHs/EVA nanocomposites are under tensile stress, the LDHs particles can shift together with the EVA resin. The tensile strength of the filling system can be improved due to the increasing of effective interface. 


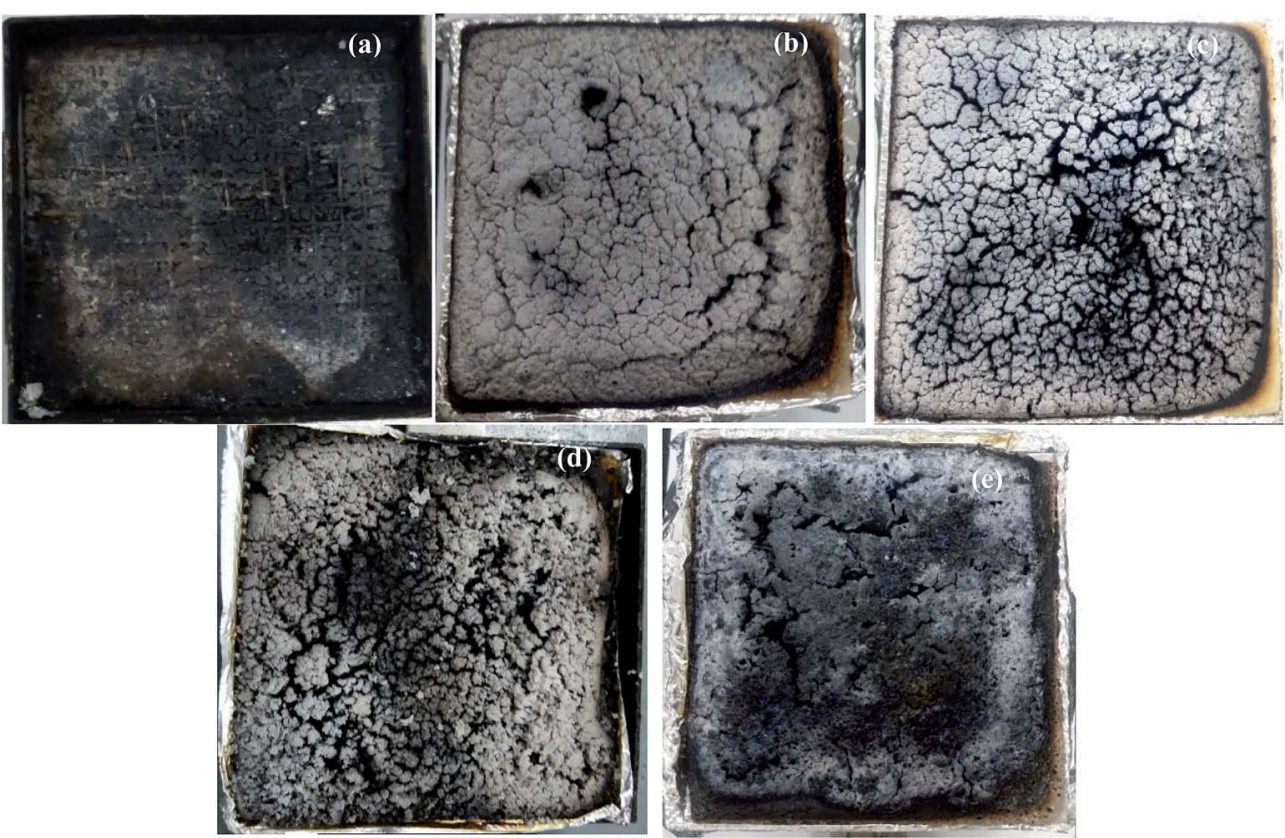

Fig. 8 Digital photographs of char residues after CCT for (a) pure EVA (b) FR-1/EVA; (c) FR-2/EVA; (d) FR-3/EVA; (e) FR-4/EVA.

Table 6 Mechanical properties of the pure EVA and FRs/EVA nanocomposites

\begin{tabular}{lll}
\hline Samples & $\begin{array}{l}\text { Tensile strength } \\
(\mathrm{MPa})\end{array}$ & $\begin{array}{l}\text { Elongation at } \\
\text { break }(\%)\end{array}$ \\
\hline Pure EVA & 29 & 800 \\
FR-1/EVA & 12.0 & 620 \\
FR-2/EVA & 8.06 & 410 \\
FR-3/EVA & 10.11 & 500 \\
FR-4/EVA & 13.38 & 620 \\
\hline
\end{tabular}

The elongation at break of composites decreased greatly when different FRs were added, because of the high additive amount of FRs are unfavourable for the toughness of FRs/EVA. As the additive amount up to $40 \mathrm{wt} \%$ FRs are more rigid and difficult to deform, the elongation at break of FRs/EVA are mainly borne by EVA under the action of stress. The actual elongation at break of the polymer is greater than the apparent elongation at break. Therefore, the elongation at break values of FRs/EVA are lower than that of pure EVA.

\section{Micromorphology}

The morphologies and microstructures of combustionfractured cross sections and freeze-fractured cross sections of pure EVA and FRs/EVA nanocomposites are shown in Fig. 9 and 10. Fig. 9 shows the surface morphologies of the char residues of EVA and FRs/EVA nanocomposites obtained after UL-94 vertical burning test. It can be found that the charred layers of FR-1/EVA, FR-2/EVA and FR-3/EVA were very loose and have some bigger holes, some small molecular gaseous decomposition products evolved from FR-1/EVA, FR-2/EVA, FR-3/EVA through the relatively weak layer. The presence of larger hole in the charred layers of FRs/EVA, affecting their flame retardant properties, which corresponds well with the fact that the LOI values of FR-1/EVA, FR-2/EVA, FR-3/EVA are all lower than that of FR-4/EVA, as shown in the Table 4. From the char structure of SEM, it can explain the combustion phenomenon of the FRs/ EVA, which correlates well with mass results of thermal degradation.

A compact and intumescent charred layer can be formed on the surface of the FR-4/EVA. This charred layer provides an efficient shield and insulation, prohibiting the underlying material from contacting with heat, oxygen and fire directly. FR4 decomposition products $\left(\mathrm{MgO}, \mathrm{Al}_{2} \mathrm{O}_{3}, \mathrm{ZnO}\right.$, and $\mathrm{SnO}_{2}$ ) promote formation of compact charred layers on the surface of EVA. Contrast surface morphologies of the char residues of the FRs/EVA, it is found that FR-4/EVA has more compact structures than those from other FRs/EVA, which presents the further evidence on the mechanism that synergistic effects between two-component acidic ions $\mathrm{SnO}_{3}{ }^{2-}$ and $\mathrm{CO}_{3}{ }^{2-}\left(\mathrm{SnO}_{3}{ }^{2-} / \mathrm{CO}_{3}{ }^{2-}=\right.$ $1: 1)$ significantly enhance the flame retardant properties of FR4/EVA, consistent with Table 4.

Fig. 10 shows the SEM images of freeze-fractured cross sections of pure EVA and FRs/EVA nanocomposites sample bars. Large LDHs particles dispersed irregularly in the EVA matrix were shown in Fig. 10(b)-(d). It is suggested that the synthesized LDHs particles have many active $-\mathrm{OH}$ groups in the surface structure, thus the composite particles is unstable with high surface energy. And it tends to form hydrogen bonds easily, resulting in soft agglomeration. Hard agglomeration can also happen during condensation of surface hydroxyl groups or coordinated water molecules. However, a good dispersion of LDHs in the EVA matrix is necessary for better flame retardant. It is difficult to obtain good dispersion of LDHs in the EVA matrix by simple physical 

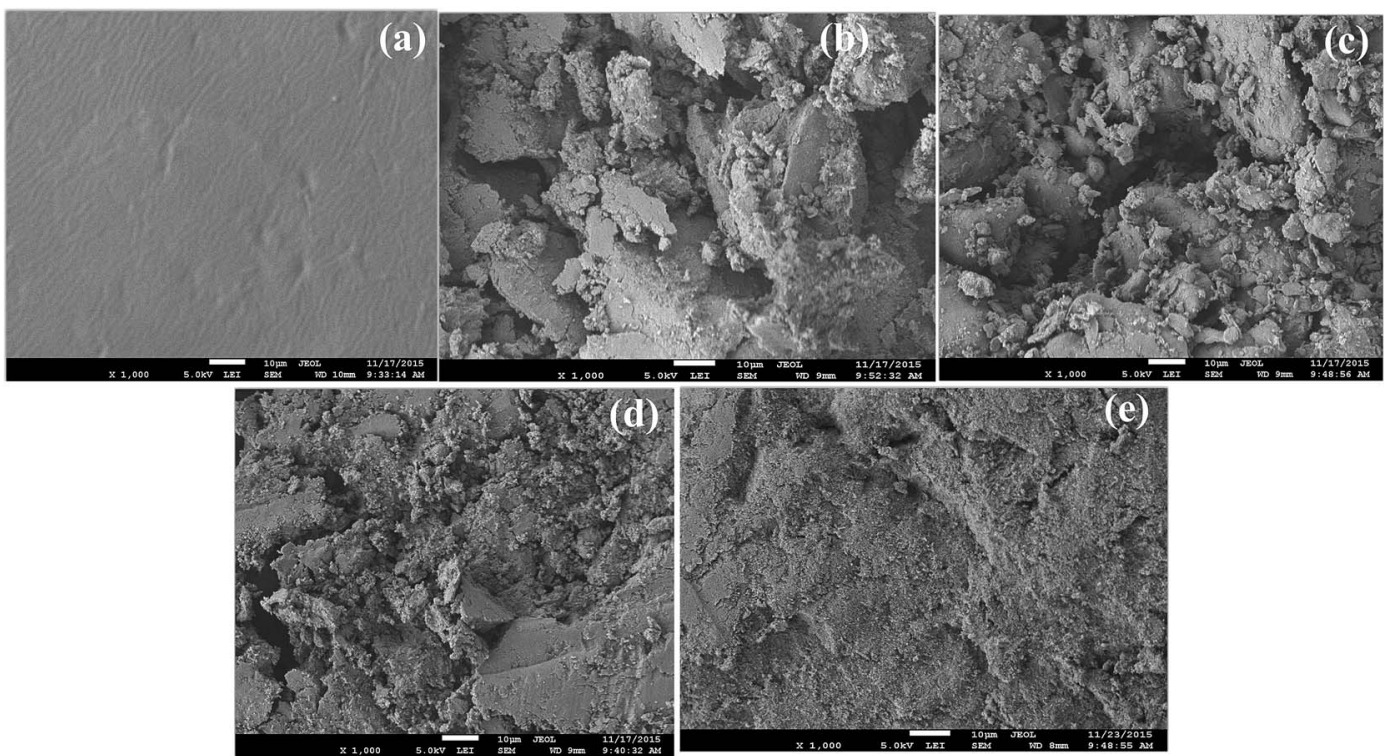

Fig. 9 SEM images of the char residues of (a) pure EVA; (b) FR-1/EVA; (c) FR-2/EVA; (d) FR-3/EVA; (e) FR-4/EVA obtained after UL-94 vertical burning test.

blending due to their poor compatibility. High loading (40 wt\%) of flame retardants can destroy the continuities of polymer chains and give rise to the deterioration of mechanical property and processability (Table 6). From Fig. 10(e), it was found that the LDHs particles of FR-4 distributed uniformly in EVA matrix. Compared with FR-1, FR-2, and FR-3, FR-4 is more compatible with polymers. Tensile strength and elongation at breakage point of FR-4 were also better than those of FR-1, FR-2, and FR-3, as shown in Table 6. This is an indication that the FR-4 is stiffening the EVA matrix and acting as reinforcements.

\section{Flame retardant mechanism}

The mechanism of the synergistic flame retardant effects between two-component acidic ions intercalated layered double hydroxide (MgAlZn- $\mathrm{X}_{1} / \mathrm{X}_{2}$-LDHs) was analyzed as follows. The FRs act in both the gas phase and the condensed phase, their thermal decomposition follows endothermic reaction to decrease the temperature of materials. During the combustion of FRs/EVA nanocomposites, $\left[\mathrm{Mg}_{4} \mathrm{Al}_{2} \mathrm{Zn}_{2}(\mathrm{OH})_{16} \mathrm{X}_{1} \mathrm{X}_{2}\right] \cdot 4 \mathrm{H}_{2} \mathrm{O}$ lose interlayer water, the hydroxyl groups in the layers and intercalated $\mathrm{CO}_{3}{ }^{2-}$ anions, and which vaporized into water vapor and $\mathrm{CO}_{2}$. These processes are endothermic reaction, and then

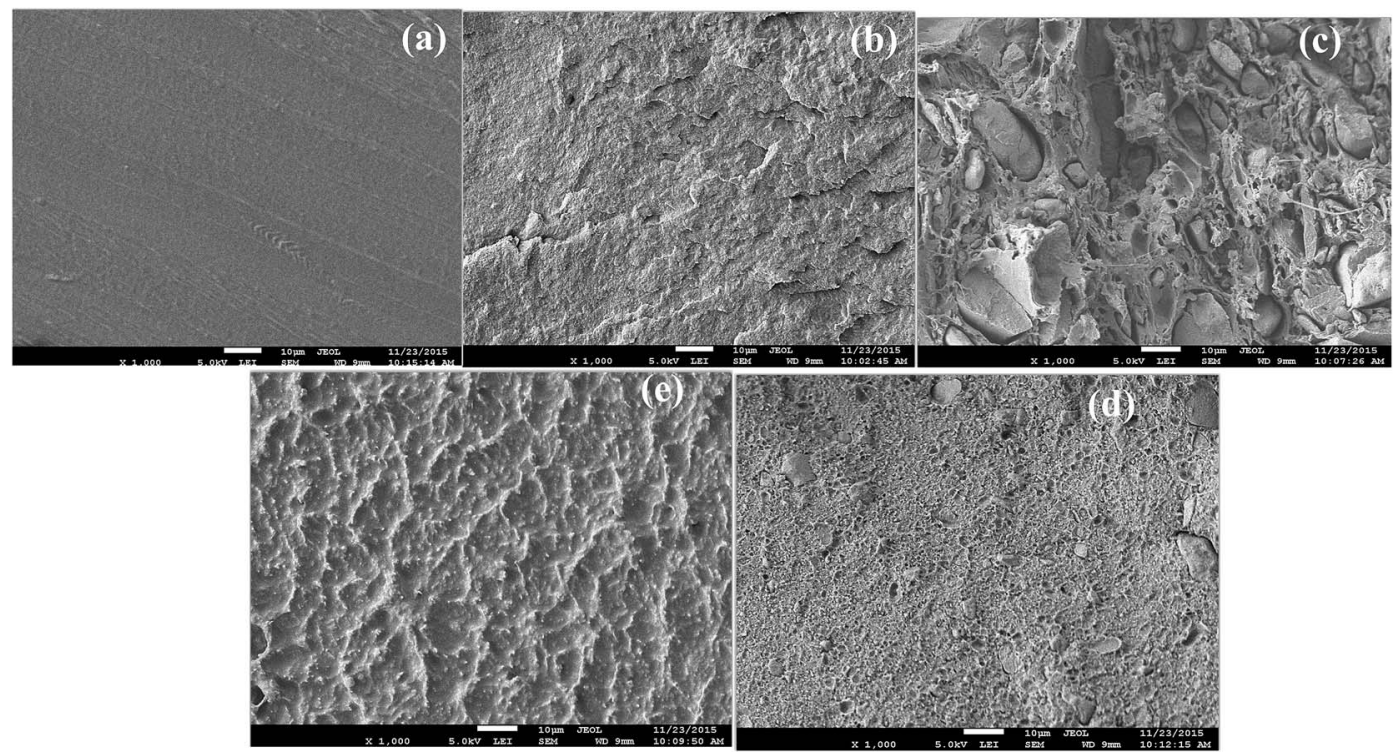

Fig. 10 SEM images of (a) pure EVA; (b) FR-1/EVA; (c) FR-2/EVA; (d) FR-3/EVA; (e) FR-4/EVA obtained after freeze-fractured cross sections in liquid nitrogen. 
decrease the surface temperature of FRs/EVA nanocomposites, retard the thermal degradation of materials, diluting the concentration of oxygen, and hence functioning as a heat sink in the gas phase. Additionally, during combustion, $\left[\mathrm{Mg}_{4} \mathrm{Al}_{2}\right.$ $\left.\mathrm{Zn}_{2}(\mathrm{OH})_{16} \mathrm{X}_{1} \mathrm{X}_{2}\right] \cdot 4 \mathrm{H}_{2} \mathrm{O}$ lose intercalated anions $\left(\mathrm{BO}_{2}{ }^{-}, \mathrm{PO}_{4}{ }^{3-}\right.$, $\left.\mathrm{SiO}_{3}{ }^{2-}, \mathrm{SnO}_{3}{ }^{2-}\right)$ and laminates cations $\left(\mathrm{Mg}^{2+}, \mathrm{Zn}^{2+}, \mathrm{Al}^{3+}\right)$, and they dehydroxylate to a mixed metal oxides $\left(\mathrm{MgO}, \mathrm{Al}_{2} \mathrm{O}_{3}, \mathrm{ZnO}\right.$, $\mathrm{B}_{2} \mathrm{O}_{3}, \mathrm{P}_{2} \mathrm{O}_{5}, \mathrm{SiO}_{2}$ and $\mathrm{SnO}_{2}$ ), the formation of metal oxides contributes to the creation of char residues. The higher char residues resulted in quenching the flame which means less EVA matrix converted into inflammable. Created a barrier effect on the surface of FRs/EVA nanocomposites served as a thermal insulating barrier, which could slow down the heat and mass transfer and prevent the underlying material from further combustion. The larger specific surface area of mixed metal oxides generated from decomposition of LDHs at high temperature, which can better adsorb the acidic smoke and inhibit its spread, especially zinc oxides. From the above analysis, compared with FR-1/EVA, FR-2/EVA, FR-3/EVA, FR-4/EVA exhibits the highest LOI values, the lowest MSD values, the least HRR values, the least THR values, the smallest SPR values, the most char residues, mainly due to the fact that, the synergistic effects between two-component acidic ions $\mathrm{SnO}_{3}{ }^{2-}$ and $\mathrm{CO}_{3}{ }^{2-}\left(\mathrm{SnO}_{3}{ }^{2-} / \mathrm{CO}_{3}{ }^{2-}=1: 1\right)$ can lost more water vapour, promote more char residues, absorb more smoke, which decrease the surface temperature, inhibits the further decomposition of FR-4/EVA and decreases the release of smoke during combustion. At the same time, the presence of tin element in the FR-4 can also lead to the increase in LOI values and further decreases in MSD values. Tin-based compounds are known to be effective flame retardant and smoke suppressants, acting both in the gas and condensed phases. ${ }^{1}$ The synergistic flame retardant and smoke suppressants effects between twocomponent acidic ions intercalated layered double hydroxide (MgAlZn- $\mathrm{X}_{1} / \mathrm{X}_{2}$-LDHs) were favored to enhance the flame retardant and smoke suppression of the FR-4/EVA.

The flame-retardant behaviour of LDHs/EVA nanocomposite was characterized by three widely used test methods: limit oxygen index (LOI), vertical burning test (UL-94) and smoke density test. When the additive amount up to $40 \mathrm{wt} \%$, the resulting LOI values and MSD values of the $\mathrm{MgAlZn}-\mathrm{SnO}_{3}{ }^{2-} / \mathrm{CO}_{3}{ }^{2-}-\mathrm{LDH} / \mathrm{EVA}$ reached $29 \%$ and decreased by 2.98 , respectively. According to literature, ${ }^{55}$ when the additive amount of intercalated-LDH in EVA increasing by $10 \mathrm{wt} \%$, the LOI values could improve at least $5 \%$. However, when the additive amount of single-component acidic ion intercalated-LDHs ( $\mathrm{MgAl}-\mathrm{CO}_{3}{ }^{2-}$-LDHs and $\mathrm{MgAl}^{-} \mathrm{BO}_{2}{ }^{-}-\mathrm{LDHs}$ ) is higher up to $60 \mathrm{wt} \%$, the LOI only increasing $1 \%$ and $0.2 \%$ (ref. 40) than $\mathrm{MgAlZn-SnO}{ }_{3}{ }^{2-} / \mathrm{CO}_{3}{ }^{2-}$-LDHs/EVA, respectively. This indicated that, at the same additive amount of LDHs in EVA, the LOI value of two-component acidic ions intercalatedLDHs/EVA is relatively higher than single-component acidic ion intercalated-LDHs. Additionally, the MSD of the MgAl$\mathrm{CO}_{3}{ }^{2-}$-LDHs/EVA and $\mathrm{MgAl}-\mathrm{BO}_{2}{ }^{-}$-DHs/EVA reach up to 133.1

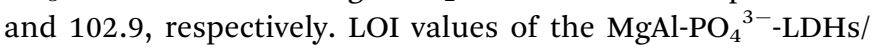
EVA is higher than the MgAlZn-SnO ${ }_{3}{ }^{2-} / \mathrm{CO}_{3}{ }^{2-}-\mathrm{LDHs} / \mathrm{EVA}$,

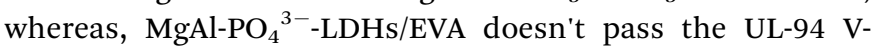
0 rating $^{39}$ (details are presented in Table 7 ). It can be seen by comparison that the flame retardant and smoke suppression effects of two-component acidic ions intercalated-LDH/EVA are relatively higher than those measured from singlecomponent acidic ion intercalated-LDH/EVA.

\section{Conclusions}

In this work, a series of two-component acidic ions intercalated layered double hydroxide (MgAlZn-X $1 / \mathrm{X}_{2}$-LDHs) were synthesized, and were further applied as a nanoflameretardant in EVA, respectively. The structure of LDHs was confirmed by XRD, FTIR and SEM, and the microstructure of FRs/EVA of combustion-fractured cross sections and freezefractured cross sections were confirmed by SEM. Morphological study shows that, due to the microwave crystallization, the average nanoscale crystal sizes of the LDHs samples are smaller and enhances the compatibility LDHs particles with the EVA matrix, a compact and intumescent charred layer can be formed on the surface of the FR-4/EVA which can insulate the polymer substrate from the heat source. TGA results indicate that FR-4 was effective thermal stability for EVA, explaining the outstanding fire performance in LOI values. The inflammability of pure EVA and FRs/EVA is compared. The results indicate that FR-4 acts in the gas phase, releasing water, quenching the flame and diluting the combustible gaseous products, and acts in the condensed phase, by promoting charring and preventing heat and mass transfer. The increase in LOI values and further decreases in MSD values arise from the presence of tin element in the FR-4. The CCT results show that FR-4 can significantly decrease the smoke production and heat release of EVA. The meanwhile, the synergistic effects between two-component acidic ions of LDHs were favored to enhance the flame retardant and smoke suppression of the FR-4/EVA. The strategy described here could provide a promising method in the development of a novel, smoke suppression and efficient two-component acidic ions intercalated layered double hydroxide flame retardant for polymer nanocomposite applications.

Table 7 Comparison on flame retardant performance of various single-component acidic ions intercalated layered double hydroxide

\begin{tabular}{|c|c|c|c|c|}
\hline Materials & Additive amount (\%) & LOI (\%) & UL-94 & MSD \\
\hline $\mathrm{MgAl}-\mathrm{CO}_{3}-\mathrm{LDH}$ & LDH/EVA $(28)=60: 40$ & 30.0 & - & 133.1 \\
\hline $\mathrm{MgAl}-\mathrm{BO}_{2}-\mathrm{LDH}$ & LDH/EVA $(28)=60: 40$ & 29.2 & - & 102.9 \\
\hline MgAlZn-SnO ${ }_{3}{ }^{2-} / \mathrm{CO}_{3}{ }^{2-}-$ LDHs (this work) & LDH/EVA $(28)=40: 60$ & 29 & $\mathrm{~V}-0$ & 2.98 \\
\hline
\end{tabular}




\section{Conflicts of interest}

There are no conflicts to declare.

\section{Acknowledgements}

The authors would like to acknowledge the financial support from the National Natural Science Foundation of China (21574021), Natural Science Foundation of Fujian Province (2016J01212) and State Key Laboratory of Comprehensive Utilization of Low-Grade Refractory Gold Ores (Zijin Mining Group Co., Ltd.).

\section{References}

1 X. R. Zheng and P. A. Cusack, Fire Mater., 2013, 37, 35-45. 2 X. D. Qian, L. Song, Y. Hu and R. K. K. Yuen, Thermochim. Acta, 2013, 552, 87-97.

3 E. Çakmakçı and A. Güngör, Polym. Degrad. Stab., 2013, 98, 927-933.

4 A. Abou-Okeil, S. M. El-Sawy and F. A. Abdel-Mohdy, Carbohydr. Polym., 2013, 92, 2293-2298.

5 S. L. Waaijers, D. Kong, H. S. Hendriks, C. A. de Wit, I. T. Cousins, R. H. S.Westerink, P. E. G. Leonards, M. H. S. Kraak, W. Admiraal, P. de Voogt and J. R. Parsons, Rev. Environ. Contam. Toxicol., 2013, 222, 1-71.

6 Q. Lv, J. Q. Huang, M. J. Chen, J. Zhao, Y. Tan, L. Chen and Y. Z. Wang, Ind. Eng. Chem. Res., 2013, 52, 9397-9404.

7 M. Rakotomalala, S. Wagner and M. Döring, Materials, 2010, 3, 4300-4327.

8 A. Dasari, Z. Z. Yu, G. P. Cai and Y. W. Mai, Prog. Polym. Sci., 2013, 38, 1357-1387.

9 R. Sonnier, A. Viretto, L. Dumazert, M. Longerey, S. Buonomo, B. Gallard, C. Longuet, F. Cavodeau, R. Lamy and A. Freitag, Polym. Degrad. Stab., 2016, 128, 228-236.

10 L. L. Wang, M. L. Zhang and B. Li, Appl. Sci., 2016, 6, 131143.

11 A. Edenharter, P. Feicht, B. Diar-Bakerly, G. Beyer and J. Breu, Polymer, 2016, 91, 41-49.

12 P. K. Kaul, A. J. Samson, G. T. Selvan, I. Enoch and P. M. Selvakumar, Appl. Clay Sci., 2017, 135, 234-243.

13 F. Cavodeau, A. Viretto, B. Otazaghine, J. M. Lopez-Cuesta and C. Delaite, Polym. Degrad. Stab., 2017, 144, 401410.

14 L. L. Wang, M. L. Zhang and B. B. Zhou, Appl. Sci., 2017, 7, $55-67$.

15 M. W. Zhang, Z. S. Luo, M. Zhou, G. G. Zhang, K. A. Alamry, L. A. Taib, A. M. Asiri and X. C. Wang, Appl. Catal., B, 2017, 210, 454-461.

16 W. J. Liu, J. Bao, M. L. Guan, Y. Zhao, J. B. Lian, J. X. Qiu, L. Xu, Y. P. Huang, J. Qian and H. M. Li, Dalton Trans., 2017, 46, 8372-8376.

17 Y. Li, H. Y. Bi, H. Li, X. M. Mao and Y. Q. Liang, Mater. Sci. Eng., C, 2017, 78, 886-891.

18 Z. Bouaziz, M. A. Djebbi, L. Soussan, J. M. Janot, A. B. H. Amara and S. Balme, Mater. Sci. Eng., C, 2017, 76, 673-683.
19 H. Asiabi, Y. Yamini, M. Shamsayei and E. Tahmasebi, Chem. Eng. J., 2017, 323, 212-223.

20 L. J. Ma, S. M. Islam, H. Y. Liu, J. Zhao, G. B. Sun, H. F. Li, S. L. Ma and M. G. Kanatzidis, Chem. Mater., 2017, 29, 3274-3284.

21 S. M. Xu, H. Yan and M. Wei, J. Phys. Chem. C, 2017, 121, 2683-2695.

22 W. D. Liu, S. M. Xu, Z. X. Li, R. Z. Liang, M. Wei, D. G. Evans and X. Duan, Chem. Mater., 2016, 28, 5426-5431.

23 K. Q. Zhou, R. Gao and X. D. Qian, J. Hazard. Mater., 2017, 338, 343-355.

24 S. Q. Liang, L. F. Zhang, Z. L. Chen and F. Fu, BioResources, 2017, 12, 533-545.

25 L. Moyo, S. S. Ray, W. Sebati and V. Ojijo, J. Appl. Polym. Sci., 2017, 134, 45024-45038.

26 S. L. Xu, L. X. Zhang, Y. J. Lin, R. S. Li and F. Z. Zhang, J. Phys. Chem. Solids, 2012, 73, 1514-1517.

27 A. Leuteritz, B. Kutlu, J. Meinl, D. Wang, A. Das, U. Wagenknecht and G. Heinrich, Mol. Cryst. Liq. Cryst., 2012, 556, 107-113.

28 K. Q. Zhou, Z. Gui and Y. Hu, Polym. Adv. Technol., 2017, 28, 386-392.

29 X. D. Wang and Q. Zhang, Polym. Int., 2004, 53, 698-707.

30 L. Shen, Y. H. Chen and P. L. Li, Composites, Part A, 2012, 43, 1177-1186.

31 L. L. Wang, B. Li, X. C. Zhang, C. X. Chen and F. Zhang, Appl. Clay Sci., 2012, 56, 110-119.

32 D. Y. Wang, A. Leuteritz, B. Kutlu, M. A. D. Landwehr, D. Jehnichen, U. Wagenknecht and G. Heinrich, J. Alloys Compd., 2011, 509, 3497-3501.

33 C. M. Becker, A. D. Gabbardo, F. Wypych and S. C. Amico, Composites, Part A, 2011, 42, 196-202.

34 L. J. Wang, X. L. Xie, S. P. Su, J. X. Feng and C. A. Wilkie, Polym. Degrad. Stab., 2010, 95, 572-578.

35 W. Z. Xu, B. L. Xu, A. J. Li, X. L. Wang and G. Wang, Ind. Eng. Chem. Res., 2016, 55, 11175-11185.

36 W. Z. Xu, B. L. Zhang, X. L. Wang and G. S. Wang, RSC Adv., 2017, 7, 19662-19673.

37 Q. Wang, J. P. Undrell, Y. S. Gao, G. P. Cai, J. C. Buffet, C. A. Wilkie and D. O'Hare, Macromolecules, 2013, 46, 6145-6150.

38 E. N. Kalali, X. Wang and D. Y. Wang, J. Mater. Chem. A, 2016, 4, 2147-2157.

39 L. Ye and B. J. Qu, Polym. Degrad. Stab., 2008, 93, 918-924.

40 L. Shi, D. Q. Li, J. R. Wang, S. F. Li, D. G. Evans and X. Duan, Clays Clay Miner., 2005, 53, 294-300.

41 S. Cravanzola, F. Cesano, G. Magnacca, A. Zecchina and D. Scarano, RSC Adv., 2016, 6, 59001-59008.

42 X. Wang, S. Zhou, W. Y. Xing, B. Yu, X. M. Feng, L. Song and Y. Hu, J. Mater. Chem. A, 2013, 1, 4383-4390.

43 M. Z. B. Hussein and T. K. Hwa, J. Nanopart. Res., 2000, 2, 293-298.

44 X. Y. Pang, Y. Tian and X. Z. Shi, J. Appl. Polym. Sci., 2017, 134, 44634-44643.

45 J. Liu, W. H. Bing, X. G. Xue, F. Wang, B. Wang, S. He, Y. K. Zhang and M. Wei, Catal. Sci. Technol., 2016, 6, 39763983. 
46 M. P. Bernardo, F. K. V. Moreira, L. A. Colnago and C. Ribeiro, Colloids Surf., A, 2016, 497, 53-62.

47 X. F. Yang, P. Roonasi and A. Holmgren, J. Colloid Interface Sci., 2008, 328, 41-47.

48 Y. J. Liu, L. Mao and S. H. Fan, J. Appl. Polym. Sci., 2014, 131, 8964-8973.

49 G. R. Wang, D. Rao, K. T. Li and Y. J. Lin, Ind. Eng. Chem. Res., 2014, 53, 4165-4172.

50 F. Rey and V. Fornes, J. Chem. Soc., Faraday Trans., 1992, 88, 2233-2238.
51 X. L. Chen, C. Y. Ma and C. M. Jiao, $R S C A d v .$, 2016, 6, 6740967417.

52 C. M. Jiao, H. Z. Wang, S. X. Li and X. L. Chen, J. Hazard. Mater., 2017, 332, 176-184.

53 X. L. Chen, W. D. Wang and C. M. Jiao, $R S C A d v ., 2016,6$, 92276-92284.

54 L. Liu, J. Hu, J. L. Zhuo, C. M. Jiao, X. L. Chen and S. X. Li, Polym. Degrad. Stab., 2014, 104, 87-94.

55 L. L. Wang, Preparation of $L D H$ containing nickel and investigation of LDH/EVA composite, Northeast Forestry University, 2011. 